\title{
Isotope characteristic of snow cover in Tomsk
}

\author{
Daria Kalashnikova ${ }^{1}$, Galina Simonova ${ }^{1, *}$, Yuriy Volkov $^{1}$, and Anna Markelova ${ }^{1}$ \\ ${ }^{1}$ Institute of Monitoring of Climatic and Ecological Systems of SB RAS, 634055, 10/3, \\ Academichesky Ave., Tomsk, Russia
}

\begin{abstract}
The snow cover has a high sorption ability that way it is a source of information in identifying anthropogenic pollution of the environment, and it also contains a climate signal. Results of studies of the oxygen and hydrogen isotope composition of snowmelt and the carbon isotope composition of black carbon extracted from the dispersed fraction of the atmospheric aerosols deposited on the snow cover during the winter periods of 2016-2018 years are shown in the paper. The relationships between air temperature, the amount of precipitation and the isotope oxygen and hydrogen composition of melting snow are analyzed.
\end{abstract}

\section{Introduction}

The isotope composition of precipitation is an important parameter, knowledge of which is necessary in hydrological, meteorological, paleoclimatic and environmental researches. The values of the isotope composition of hydrogen and oxygen of atmospheric precipitation are used as important climatic parameters in studying atmospheric humidity cycles, hydrological and glaciological cycles [1], and also used as a basis for the paleotemperatures reconstruction in the studies of ice cores [2].

Snow cover is an informative indicator of aerogenic pollution, because atmospheric pollutions accumulate naturally at it. One such pollutant is black carbon (BC) or pyrogenic carbon, which is formed during incomplete combustion of fossil fuels, biofuels and biomass. $\mathrm{BC}$ is the main component of soot, which in addition to it also contains organic carbon. Although BC exists in the atmosphere for a short time, it has a significant impact on climate, ecology and public health.

Unfortunately, the amount of researches in which the isotope composition of precipitation and air particulate matter which deposited to snow cover is investigated, is small for Russia. However, there are a number of studies for individual regions [1, 3, 4]. The purpose of our work is studying of oxygen and hydrogen isotope composition of winter atmospheric precipitation and the isotope composition of carbon from air particulate matter deposited on snow cover in Tomsk and its vicinities.

\section{Materials and methods}

Snow cover was sampled at 17 sites in March, 2016, 2017 and 2018.

*Corresponding author: galina_simonova@inbox.ru 
Six sampling sites (1-6) are located outside the city (Tomsk) and are considered as background. The rest sampling sites are located at sites with different degree of anthropogenic loading inside the city (industrial enterprises, power plants, and transport).

Snow cores selected using a plastic pipe with scale of depth and with a diameter of 10 $\mathrm{cm}$ by applying an envelope method according to a technique [5]. Then samples were packed into leakproof plastic bags and were delivered to laboratory. Melting of snow happened in laboratory conditions at the room temperature. Snowmelt was filtered. The total carbon content and carbon isotope composition was determined in the particulate matter deposited to snow cover and also black carbon was extracted from them. Snowmelt was analyzed on isotope composition of oxygen and hydrogen.

Air particulate matters are a combination of three types of carbon: inorganic (carbonates), organic (for example, humic substances and plant material) and the pyrogenic (black) carbon. Extraction of BC was carried out according to the technique offered in work [6]. Treated BC samples were washed with the deionized water, centrifuged and dried. 500 $\mu \mathrm{g}$ of the $\mathrm{BC}$ samples were placed in tin capsules and combusted in the oxidation-reduction reactor of the element analyzer.

$5 \mu \mathrm{L}$ of snowmelt samples were located in vials and were flushed by gas mixture. A gas mixture of $0.5 \% \mathrm{CO}_{2}$ in $\mathrm{He}$ was used in the analysis of oxygen isotope composition. The catalytic platinum sticks were inserted into vials with samples and a gas mixture of $2 \% \mathrm{H}_{2}$ in He was used in the analysis of hydrogen isotope composition. After a flush the analysis of isotope composition of water was carried out by method of isotope equilibration: for hydrogen in 40 min and for oxygen in 8 hours.

The isotope analysis of the dispersed fraction of atmospheric aerosols was carried out using the Flash 2000 Elemental analyzer, and analysis of snowmelt was carried out using the GasBench II system. Elemental analyzer and GasBench II system are coupled to DELTA V Advantage isotope ratio mass spectrometer (Tomsk Regional Council of Tomsk Scientific Center SB RAS).

Hydrogen, carbon and oxygen isotope compositions $\left(\delta^{2} \mathrm{H}\right.$ or $\delta \mathrm{D}, \delta^{13} \mathrm{C}$ and $\left.\delta^{18} \mathrm{O}\right)$ generally are expressed as a $\delta$ value in units of per mil according to the formula:

$$
\delta^{H} X=\left[\frac{R_{\text {sample }}}{R_{\text {standard }}}-1\right] \times 1000 .[\% 0]
$$

In this equation, the $\delta$ is specified for an element $(\mathrm{X}=\mathrm{H}, \mathrm{C}, \mathrm{O})$, the superscript $H$ gives the heavy isotope mass of that element $\left({ }^{2} \mathrm{H},{ }^{13} \mathrm{C},{ }^{18} \mathrm{O}\right)$ and $R$ is the ratio of the heavy isotope to the light isotope for the elements $-{ }^{2} \mathrm{H} /{ }^{1} \mathrm{H},{ }^{13} \mathrm{C} /{ }^{12} \mathrm{C},{ }^{18} \mathrm{O} /{ }^{16} \mathrm{O}$.

The $\delta$ value is calculated relative to standards: carbon in Vienna Pee Dee belemnite (VPDB), oxygen and hydrogen in SLAP, GISP and VSMOW. All isotope measurements were done in replicates, and standard deviation (SD) didn't exceed $\pm 0.2 \%$ for carbon, $\pm 0.3 \%$ for oxygen and $\pm 0.8 \%$ for hydrogen.

\section{Results}

\subsection{Isotope composition of snowmelt}

The results of the isotope analysis of 15 snow cover samples for the winter period (from November to March) showed that the values of $\delta^{18} \mathrm{O}$ and $\delta \mathrm{D}$ for two years vary in the ranges: from -24.4 to $-21.0 \%$ for $\delta^{18} \mathrm{O}$ and from -183.6 to $-148.2 \%$ for $\delta \mathrm{D}$ (Fig. 1).

For the background areas (1-5 sampling sites), the $\delta^{18} \mathrm{O}$ and $\delta \mathrm{D}$ values for two winter periods (2016-2017 and 2017-2018) have similar values. However, the values of both $\delta^{18} \mathrm{O}$ 
and $\delta \mathrm{D}$ for all sampling sites for the 2016-2017 winter period are lighter compared with the 2017-2018. The average values of $\delta^{18} \mathrm{O}$ and $\delta \mathrm{D}$ for the 2016-2017 and 2017-2018 winter periods are -23.4 and $-22.1 \%,-174.3$ and $-161.4 \%$, correspondingly.

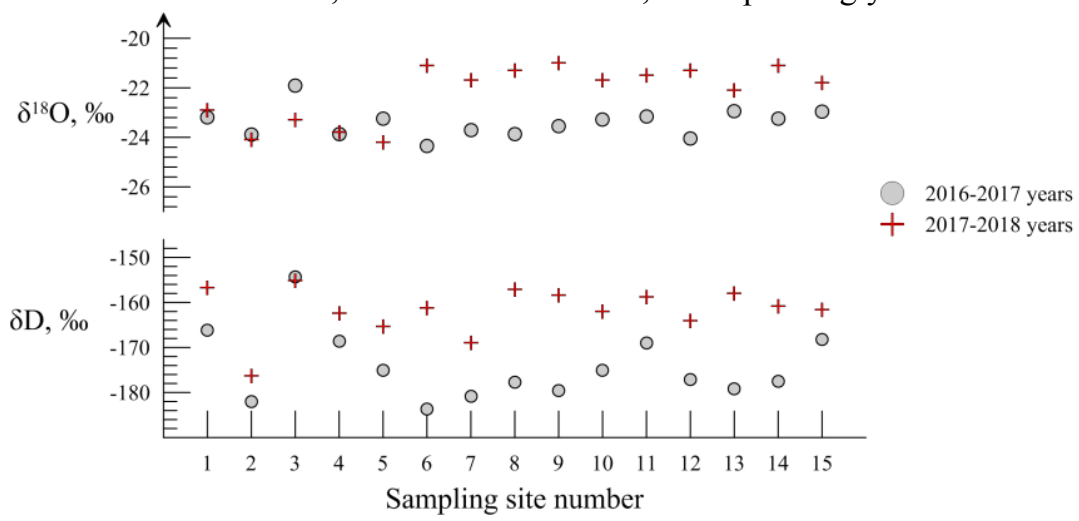

Fig. 1. The average $\delta \mathrm{D}$ and $\delta 18 \mathrm{O}$ values of snowmelt for two years.

It is a fact that the fractionation of isotopes in precipitation is primarily determined by air temperature [7]. According to the histogram of the distribution of average air temperatures (Fig. 2), the air temperatures from -15 to $0^{\circ} \mathrm{C}$ and from -20 to $0^{\circ} \mathrm{C}$ predominate in the 2016-2017 and 2017-2018 winter periods, correspondingly. However, the amount of days with low temperatures (from -30 to $-20^{\circ} \mathrm{C}$ ) is more for the 2016-2017winter period. The average values of air temperature for the 2016-2017 and 2017-2018 winter periods are approximately the same and equal to $-11.24^{\circ} \mathrm{C}$ and $-11.44^{\circ} \mathrm{C}$, respectively. This small difference in temperature $\left(0.2^{\circ} \mathrm{C}\right)$ does not explain the difference in the isotope composition of snow. Since the isotopic composition of precipitation has lighter values at lower formation temperatures, the conditions when the main part of snow cover was formed should be considered.
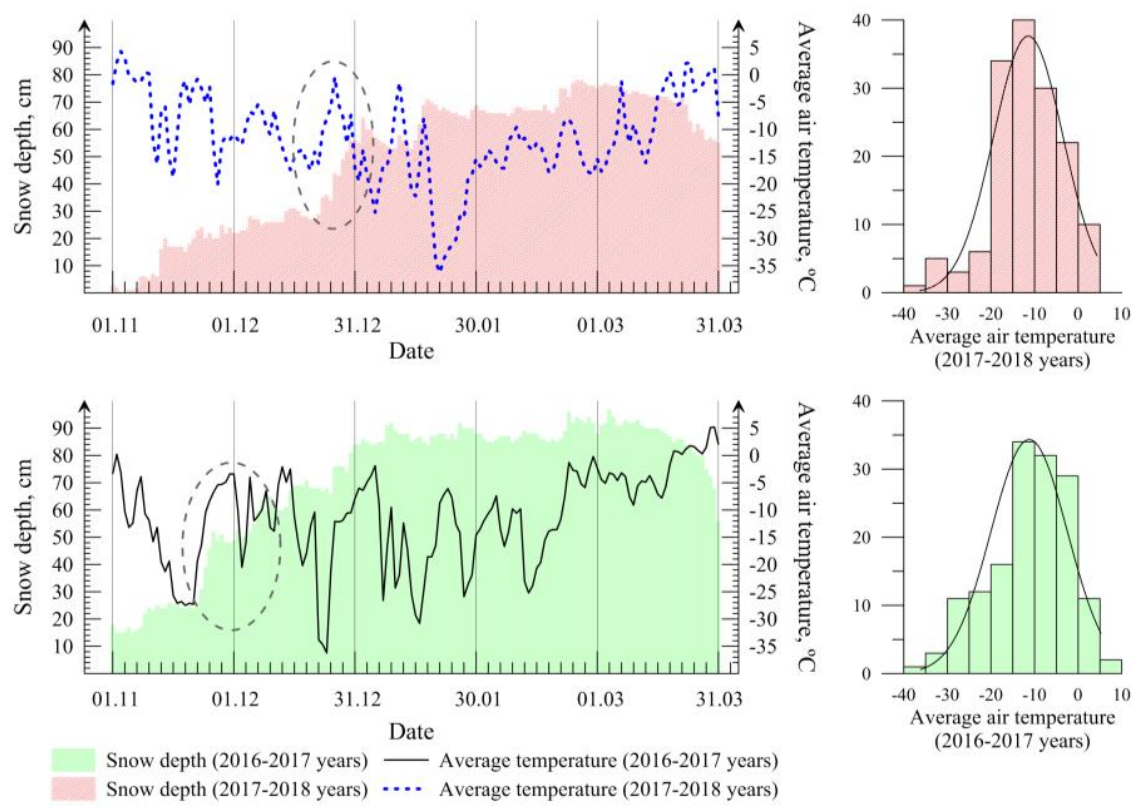

Fig. 2. The values of snow depth, average air temperatures and a histogram of air temperature distribution for the 2016-2017 and 2017-2018 winter periods. 
In the 2016-2017 winter period the main part of snow cover was formed at the end of November and at the beginning of December 2016 (Fig. 2). The air temperature in this time interval varied from -27 to $-10^{\circ} \mathrm{C}$. At the lowest temperature in December, 2016 (about $36^{\circ} \mathrm{C}$ ) the snow depth decreased due to the freezing of snow. From January to March the snow depth was almost unchanged. In the 2017-2018 winter period snow cover began to form in middle of November at temperatures from -15 to $-5^{\circ} \mathrm{C}$, and the main part of snow cover was formed at the end of December 2017 and at the beginning of January 2018, when warming from -15 to $0^{\circ} \mathrm{C}$ was observed (Fig. 2). At the lowest air temperature (around $35^{\circ} \mathrm{C}$ ) in January 2018 , the snow depth, as well as for 2016-2017 winter period, decreased due to the freezing of snow. Since in 2017-2018 winter period the main part of snow cover was formed at higher air temperatures, hence the snow samples of this winter period are characterized by a heavier isotope composition of oxygen and hydrogen.

Because the snow cores were not sampled layer-by-layer, it is not possible to obtain the equations for the dependence of the isotope composition of precipitation on the air temperature in the winter period.

\subsection{Carbone isotope composition of atmospheric aerosols deposited on snow cover}

Snow cover is a handy object for studying the arrival of air particulate matter into the atmosphere and its further redistribution. The $\delta^{13} \mathrm{C}$ variations of atmospheric aerosol deposited on the snow cover during the winter period allow comparing the values of total carbon isotope composition between years. During the past three years the $\delta^{13} \mathrm{C}$ of air particulate matter which deposited on snow cover has been analyzing in Tomsk (Fig.3).

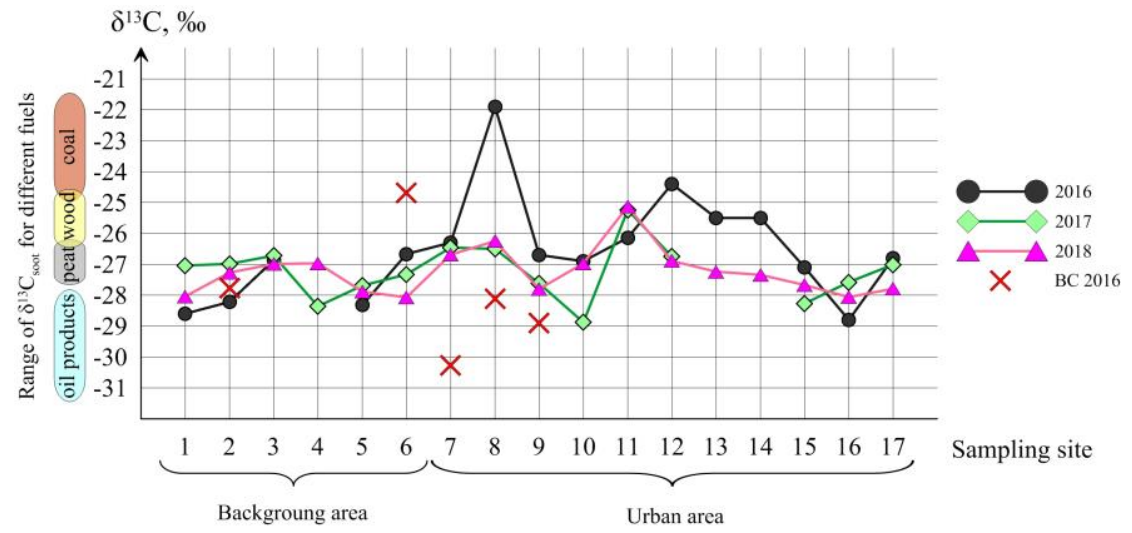

Fig. 3. Variations of the $\delta^{13} \mathrm{C}$ of air particulate matter and extracted from them black carbon (BC) for Tomsk.

The $\delta^{13} \mathrm{C}$ values of air particulate matter differ by 7\%o at different sampling points, and the percentage of carbon varies from $3 \%$ to $24 \%$. The $\delta^{13} \mathrm{C}$ for background area $(1-6$ sampling site) has similar values for three years (Fig. 3). However, for urban area, similar stability of $\delta^{13} \mathrm{C}$ values is observed in $7,9,11,15-17$ sampling site.

Considering the isotope composition of total carbon, it is difficult to determine the source of carbon origin due to the transformation of soot particles through time. However, the isotope composition of black carbon extracted from aerosol particles can be used to estimate the initial substance, i.e. fuel. We carried out laboratory studies of soot particles released during fossil fuel (coal, oil products) and biomass (wood, peat) combustion were trapped to determine the origin of pyrogenic carbon [9]. In this studies coal soot has the 
heaviest isotope composition equal to $-24.3 \%$ and the products of oil processing have the lightest isotope composition $\approx-29.7 \%$ (Fig. 3).

Only in 5 samples out of 17 we were able to extract black carbon in an amount sufficient for analysis in 2016 (Fig. 3). The $\delta^{13} \mathrm{C}$ of $\mathrm{BC}$ in samples №9 $\left(\delta^{13} \mathrm{C}=-28.1 \%\right.$ ) and №10 $\left(\delta^{13} \mathrm{C}=-28.9 \%\right.$ ), selected near roads with heavy traffic, was light. The lightest $\delta^{13} \mathrm{C}$ of $\mathrm{BC}\left(\delta^{13} \mathrm{C}=-30.3 \%\right)$ corresponds to the sampling site located near the petrochemical plant. These values of the $\delta^{13} \mathrm{C}$ of $\mathrm{BC}$ correspond to the $\delta^{13} \mathrm{C}$ of soot formed during the combustion of oil products. The heavy isotope composition $\left(\delta^{13} \mathrm{C}=-24.5 \%\right.$ ) corresponds to the samples taken near the cottage village, which is heated by coal.

\section{Conclusion}

The results of the isotope analysis of snow samples in Tomsk during winter period (from November to March) showed that the values of $\delta^{18} \mathrm{O}$ and $\delta \mathrm{D}$ vary from -24.4 to $-21.9 \%$ and from -183.6 to $-154.3 \%$, respectively in $2016-2017$, and from -24.2 to $-21 \%$ ond from -176.3 to $-155.1 \%$ respectively in $2017-2018$. First of all, the isotope fractionation in atmospheric precipitation is determined by air temperature. The key issue is that the temperature at which the maximum amount of precipitation fell has a primary importance for interpreting data of a whole snow cores. For the equation of local meteoritic precipitation line, it is necessary to take snow samples layer-by-layer after each snowfall.

The study of carbon isotope composition of dispersed fraction of atmospheric aerosol deposited on snow cover makes it possible to estimate the anthropogenic impact during the entire winter period. It is necessary to select atmospheric aerosol more frequently (for example, to glass fiber filters using air-blowing systems) for better understanding the changes in spatial and temporal variations of isotope composition of atmospheric aerosol and tracking the transfer of the latter.

The research was supported by the VIII.80.2.3 base project and the Russian Foundation for Basic Research (research project no. 16-45-700941). Meteodata were kindly provided by geophysical observatory of IMCES of SB RAS.

\section{References}

1. Yu. K. Vasil'chuk, V. P. Shevchenko, A. P. Lisitzin, et al., Doklady Earth Sciences 471(2), 1284-1287 (2016)

2. V. N. Mikhalenko, S. S. Kutuzov, A. A. Ekaykin, et al., Ice and Snow 57(3), 293-306 (2017) (in Rissian)

3. N. S. Malygina, T. S. Papina, A. N. Eyrich, et al., Science and Education 3, 10-15 (2015) (in Rissian)

4. Yu. N. Chizhova, Yu. K. Vasil'chuk, K. Yoshikawa, et al., Ice and Snow 55(3), 55-66 (2015) (in Rissian)

5. L. M. Zarina, S. M. Gildin, Geoecological workshop: a teaching aid, 60 (2011)

6. X. Wang, Z. Ding, P. Peng, Palaeography, Palaeoclimatology, Palaeoecology 315, 6174 (2012)

7. Yu. K. Vasil'chuk, V.M. Kotlyakov, Principles of isotope geocryology and glaciology, 616 (2000) (in Rissian)

8. A. N. Markelova, Y. V. Volkov, G. V. Simonova, D. A. Kalashnikova, Conference proceedings SGEM 2017, 17(41), 567-574 (2017) 
9. D.A. Kalashnikova, A.N. Markelova, V.N. Melkov, G.V. Simonova, Chemist. for Sustain. Develop., 4(24), 467-471 (2016) 